\title{
Aluminum slurry coatings to replace cadmium for aeronautic applications
}

\author{
A. Agüero *, J.C. del Hoyo, J. García de Blas, M. García, M. Gutiérrez, L. Madueño, S. Ulargui \\ Instituto Nacional de Técnica Aeroespacial (INTA), Área de Materiales Metálicos, Ctra. Ajalvir Km. 4, 28850 Torrejón de Ardoz, Madrid, Spain
}

\section{A R T I C L E I N F O}

Keywords:

Cadmium coating replacement

Aluminum slurry

Steel

Atmospheric corrosion

Aeronautical applications

\begin{abstract}
A B S T R A C T
Cadmium has been widely used as a coating to provide protection against galvanic corrosion for steels and for its natural lubricity on threaded applications. However, it is a toxic metal and a known carcinogenic agent, which is plated from an aqueous bath containing cyanide salts. For these reasons, the use of cadmium has been banned in Europe for most industrial applications. However, the aerospace industry is still exempt due to the stringent technical and safety requirements associated with aeronautical applications, as an acceptable replacement is yet to be found. Al slurry coatings have been developed as an alternative to replace cadmium coatings. The coatings were deposited on AISI 4340 steel and have been characterized by optical and electron microscopy. Testing included salt fog corrosion exposure, fluid corrosion exposure (immersion), humidity resistance, coating-substrate and paint-coating adhesion, electric conductivity, galvanic corrosion, embrittlement and fatigue. The results indicated that Al slurry coatings are an excellent alternative for Cd replacement.
\end{abstract}

\section{Introduction}

Environmental concerns and health problems have prompted governments to establish legislation banning or restricting the use of a number of materials and/or processes critical for protecting numerous components and structures within the aerospace industry $[1,2] . \mathrm{Cd}$ coatings are among those materials and are still widely used for the protection of aeronautical parts made from high strength steel alloys from atmospheric corrosion, and more over for their electrical conductivity, lubricity and solderability properties. $\mathrm{Cd}$ is anodic against steel and therefore, as a coating, sacrificially oxidizes protecting steel components exposed to a corrosive environment. However, $\mathrm{Cd}$ is an inherently toxic heavy metal poison and exposure not only occurs in the plating plant, but also when the coatings are being used in diverse applications. Thus $C d$ coatings can leach when in contact with cleaning solutions during normal use, contaminating ground water. Moreover, cyanide baths are used during the electroplating process and despite their many advantages, these salts present an important issue from the health and safety perspective [3]. Therefore, the use of Cd coatings results in environmental and health problems throughout their life cycle. Despite these important issues, the aerospace industry is still exempt from obeying the banning legislation, due to the stringent technical and safety requirements associated with this industry, as an acceptable replacement is yet to be found. However, stringent controls of the disposal of effluents from $\mathrm{Cd}$ plating operations and the levels of cadmium that may be discharged into the environment are extremely low. Moreover, the concern of eliminating noxious substances and elements both in

\footnotetext{
* Corresponding author. Tel.: +34 915291561; fax: + 34915201381. E-mail address: agueroba@inta.es (A. Agüero).
}

manufacturing and maintenance operations has led many international and European programs to investigate possible alternatives in order to eliminate the use of cadmium in aerospace by 2020 . Therefore, cadmium must be removed from the standard manufacturing and maintenance procedures of the European aircraft industry.

Several alternatives to replace $C d$ coatings are currently being explored including the following processes and materials [4]:

\subsection{Electroplating}

$\mathrm{ZnNi}, \mathrm{ZnCo}$ and $\mathrm{ZnSn}$ alloys have been deposited by this process and evaluated as alternatives [5-8]. The most promising system appears to be the deposition of alkaline $\mathrm{ZnNi}$ developed by Boeing but it contains Nickel and this material is also hazardous and being considered to be banned in Europe. Al coatings deposited by electroplating in an organic electrolyte have also been explored $[9,10]$. The coatings show very good performance but the process needs to be carried out under inert atmosphere and repair needs to be done by other processes.

\subsection{Physical vapor deposition}

Aluminum deposition by ion vapor deposition (IVD-Al) was implemented in the 70s as an alternative to $\mathrm{Cd}$ by McDonnell Douglas (now Boeing) [11]. The Ivadizer process requires large vacuum coating chambers and relatively complex equipment because a plasma needs to be generated and aluminum evaporated. The process is expensive, cannot coat the inside surface of long tubes and could require post coating glass bead peening and/or chromate conversion coating using $\mathrm{Cr}^{+\mathrm{VI}}$ and/or other sealants. Recently, another PVD process based on magnetron sputtering system has been specially designed for coating internal 
surfaces and blind cavities. This process however can be expensive due to the added steps and difficult to apply in deep blind cavities $[12,13]$. Finally some landing gear components may be too large to be accommodated in available coating chambers.

\subsection{Chemical vapor deposition}

Excellent quality Al coatings (on small specimens) have been deposited from organometallic precursors. The process is at the prototype scale stage, but requires temperatures as high as $300{ }^{\circ} \mathrm{C}$ so it is unsuitable for some applications restricted by substrate sensitivity $[14,15]$.

\subsection{Current slurry application}

The application of slurries is a low cost, and easy-to-apply process that can be used to deposit aluminum. Slurries are suspensions of particles (metallic or ceramic) on a binder-solvent system that can be applied on a substrate by means of a brush, by immersion or by spraying. After application, the coated specimen is subjected to a curing heat treatment which can also be as high (i.e. $350{ }^{\circ} \mathrm{C}$ for certain slurry formulations) in order to evaporate the solvent and set the coating. Al particle suspensions in phosphate binders applied by brush or spraying have shown promise. However, there are issues regarding hydrogen embrittlement, surface roughness, adhesion, etc. Moreover, most water-based commercial slurries contain $\mathrm{Cr}^{+\mathrm{VI}}$ (although in very low contents) $[16,17]$.

\subsection{New slurry application}

A new process for the application of an Al-slurry coating for replacement of cadmium coating for aircraft components has been developed, and the resulting coatings pass the bend adhesion as well as the embrittlement tests as opposed to the former slurry coatings according to the available published information. The coating process was developed during the Spanish project "Replacement for Toxic Coatings and Coating Processes for Aeronautic Components" (RAMPE) in which the National Institute of Aerospace Techniques (INTA) as well as several Spanish aeronautical companies and institutions participated, characterized, and evaluated it in accordance with a test protocol developed to comply with the requirements of the aeronautical industry. The coatings have been applied on AISI 4340 steel, a high strength low alloyed steel commonly used for several aircraft components such as actuators and landing gears. The coatings have been characterized by optical and electron microscopy. Testing included salt fog corrosion exposure, fluid corrosion exposure (immersion), humidity resistance, coating-substrate and paint-coating adhesion, electric conductivity, galvanic corrosion, embrittlement and fatigue. Cd-plated specimens were also tested for comparison purposes. The results have indicated that the proposed Al slurry coating is an excellent alternative for $C d$ replacement.

\section{Experimental procedure}

\subsection{Materials}

AISI 4340 steel (Fe, C: $0.38-0.43, \mathrm{Cr}_{2}: 0.70-0.90, \mathrm{Mn}: 0.60-0.80$, Mo: $0.20-0.30$, Ni: $1.65-2.00$, Si: $0.15-0.30$, Al: 0.007, P: 0.035 (max.), S: 0.04 (max.) wt.\%) was obtained from Corus Group plc (presently Tata Steels), United Kingdom. The ultimate tensile strength (ous) was $1200 \mathrm{MPa}$. The Al inorganic slurry (CERAL 34) was obtained from Gebr Morant GmbH, Germany.

\subsection{Coating deposition}

Samples to be coated were sand-blasted and vapor-degreased prior to coating. The Al slurry was applied by means of a Sagola spray gun (Minixtreme) followed by a proprietary curing process under air and was subsequently subjected to glass bead peening (GBP).

\subsection{Characterization}

\subsubsection{Microstructure observation}

Optical and electron microscopy (LEICA MEF4M and JEOL JSM-840, respectively) analyses of metallographic polished cross-sections were carried out.

\subsubsection{X-ray diffraction (XRD)}

Corrosion products were identified by means of XRD using Panalytical X'Pert PRO MRD equipment with $\mathrm{Cu} K \alpha$ radiation at $45 \mathrm{KV}$ and $40 \mathrm{~mA}$.

\subsection{Test procedures}

\subsubsection{Bend adhesion}

This test evaluates the adhesion of the coating to the substrate [18]. The specimens $(100 \times 50 \times 1.5 \mathrm{~mm}$ coupons $)$ were bent repeatedly, back and forth, to an angle of $180^{\circ}$ until rupture of the basis metal occurred. The failure region was examined for separation or peeling of the coating with a magnifying glass.

\subsubsection{Wet tape-paint coating adhesion}

This test evaluates the adhesion of a paint to flat surfaces coated with Al-slurry coating [19]. The coated specimens $(150 \times 75 \times 0.8 \mathrm{~mm})$ were painted with MIL-PRF-23377, Type 1, Class N (no chromates), epoxy primer. The samples were immersed in de-ionized water kept at room temperature and tested after $168 \mathrm{~h}$ by applying and quickly removing an adhesive tape (3M No. 250). Any signs of paint detachment imply failure.

\subsubsection{Electrical conductivity}

Measurements were carried out to evaluate the insulating or conductive nature of the coatings by measuring the coating electrical resistance with a multimeter (Agilent Technologies Mod. 34401-A Digital multimeter) on three samples $(40 \times 40 \times(0.75-1.25) \mathrm{mm})$. The final value of electrical conductivity is an average of the measurements.

\subsubsection{Unscribed and scribed salt spray fog corrosion resistance}

This test evaluates the ability of the coating to prevent corrosion of coated substrates exposed to a salt spray fog [20]. The bottom half of each specimen $(150 \times 75 \times 1.5 \mathrm{~mm})$ was scratched with an Erichsen Type 463 , scratch-tester, carbide cutter forming a " $X$ " pattern. The scribed specimens (five) were placed in a chamber and exposed to a fog generated from a $5 \mathrm{wt} . \% \mathrm{NaCl}$ aqueous solution ( $\mathrm{pH}$ within 6.5 to 7.2 ) at $35^{\circ} \mathrm{C}$. The duration of the corrosion test was $1000 \mathrm{~h}$. Prior to exposure, the edges and backside of each coated specimen were masked with a suitable corrosion protection paint. The samples were visually inspected every $24 \mathrm{~h}$. Failure is established when red corrosion products appear in any of the five specimens, not taking into account the area within $5 \mathrm{~mm}$ from the sample edges.

\subsubsection{Fhid corrosion resistance}

This test evaluates the resistance of the coating to fluids commonly employed in aircraft [21]. Three coated specimens $(40 \times 40 \times 1.5 \mathrm{~mm})$ were fully immersed for a period of 7 days in each of the liquids and at temperatures indicated in Table 1 . The specimens were visually inspected after a total of $24 \mathrm{~h}$ and $168 \mathrm{~h}$ for signs of corrosion attack, coating removal and/or discoloration as well as weight loss/gain. The exposed samples should exhibit the same degree or lower degradation (if any) as well as the same or lower weight variation than the $\mathrm{Cd}$ references. 
Table 1

Fluids and temperatures employed for the immersion test.

\begin{tabular}{lll}
\hline Fluid & Type & $\begin{array}{l}\text { Temperature } \\
\left( \pm 2{ }^{\circ} \mathrm{C}\right)\end{array}$ \\
\hline MIL-L-23699 & Oil lubricant & 70 \\
JP-8 & Fuel & 70 \\
Skydrol LD4 & Hydraulic fire-resistant fluid & 70 \\
Skydrol 500B4 & Hydraulic fire-resistant fluid & 70 \\
MIL-PRF-87257 & Hydraulic fluid & 70 \\
PD-680 Type II & Degreaser & 23 \\
Propylene Glycol/water 1:3(V) & De-icing fluid & 23 \\
Turco 6017 & Stripper & 23 \\
\hline
\end{tabular}

\subsubsection{Humidity resistance}

This test evaluates the resistance of the coating to temperature cycling in a humid environment [22]. Three specimens with the dimensions $40 \times 40 \times 1.5 \mathrm{~mm}$ were placed into a controlled temperature and humidity chamber and subjected to 10 cycles (in each cycle the temperature was increased from 30 to $60{ }^{\circ} \mathrm{C}$ with a $0.25{ }^{\circ} \mathrm{C} / \mathrm{min}$ ramp, held at $60{ }^{\circ} \mathrm{C}$ for $6 \mathrm{~h}$ and decreased to $30^{\circ} \mathrm{C}$ with a $3.75{ }^{\circ} \mathrm{C} / \mathrm{h}$ ). The relative humidity was $95 \%$. Failure was established when swelling or blisters appeared.

\subsubsection{Galvanic corrosion}

This test evaluates the susceptibility of an aluminum coating on steel to cause galvanic corrosion when in contact with an aircraft aluminum alloy [23]. The coating was applied on an AISI 4340 steel washer $(3.175 \mathrm{~mm}$ of thickness, $25.4 \mathrm{~mm}$ of external diameter and $6.75 \mathrm{~mm}$ of hole diameter), which is place in contact with AA2024 aluminum alloy blocks $(80 \times 80 \times 3 \mathrm{~mm})$. Three specimens, assembled as shown in Fig. 1 with a torque value of $7.9-9 \mathrm{~N} \cdot \mathrm{m}$, were tested for a week in a neutral salt fog chamber [20]. Before and after exposure, the electrical resistance (on the block, between the block and the test washer, between the block and the screw, and between the screw and the test washer) was measured using a digital multimeter (Agilent Technologies mod. 34401-A). The maximum reading of the measurements, carried out between the washer and the test block before exposing the samples to salt fog corrosion, was always adjusted to a maximum of $2 \mathrm{~m} \Omega$ in order to ensure good electrical contact by tightening the nut. Electrical insulation between the washer and the test block on one side and the screw on the other, was always

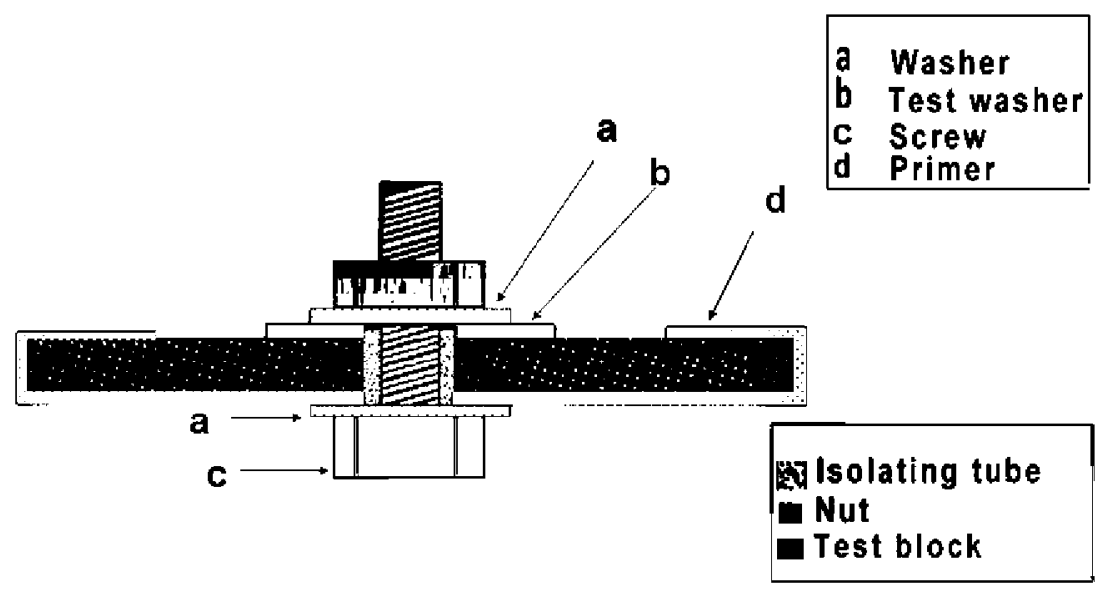

Fig. 1. Galvanic corrosion test specimen.
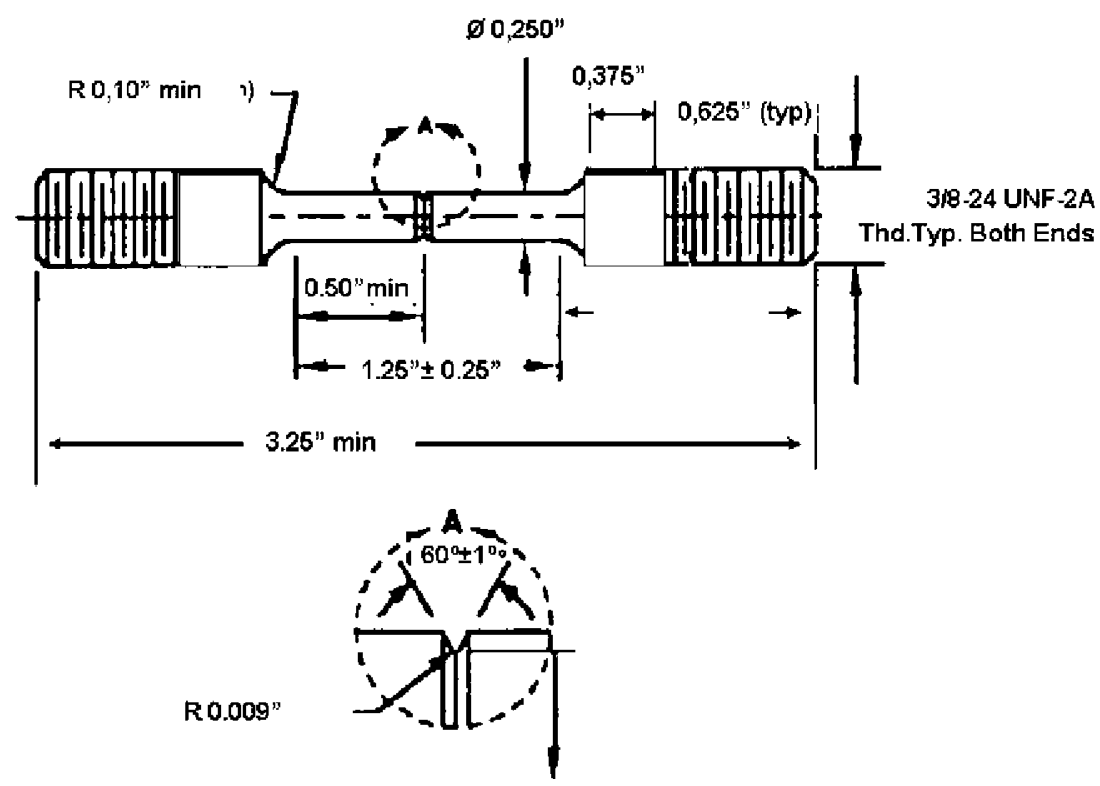

$\emptyset 0,175 "$

Fig. 2. Embrittlement test specimen. 
Table 2

Number of specimens - stress level.

\begin{tabular}{lllll}
\hline Stress $(\mathrm{MPa})$ & $\% \sigma_{\text {us }}$ & 4340 & $4340+\mathrm{Cd}$ & $4340+$ Al-slurry \\
\hline 510 & 43 & - & 6 & - \\
630 & 53 & 3 & 6 & 1 \\
645 & 54 & - & - & 6 \\
670 & 56 & 6 & 6 & 6 \\
710 & 59 & 6 & 6 & 6 \\
730 & 61 & - & - & - \\
750 & 63 & 6 & 6 & 6 \\
790 & 66 & 6 & - & - \\
Total & & 27 & 30 & 25 \\
\hline
\end{tabular}

$\sigma_{\mathrm{us}}=1200 \mathrm{MPa}$.

ensured. At the end of each test, the test specimen was detached and visually inspected, evaluating the corrosion products on the test washer, the block, and at the contact surface between each other.

\subsubsection{Hydrogen embrittlement}

This test is carried out to determine if hydrogen has diffused into the substrate during the coating process, rendering it brittle and prone to fracture [24]. The test was performed using four SATEC Testing Machines (mod. EE) with accuracy class 0.5 . The test specimens used were ASTM F519 Type 1a.1 (standard sized specimen for the sustained load test as shown in Fig. 2), in batches of four, tested at the same time. Previously, the notched fracture strength (NFS) was obtained using three bare specimens. The coated specimens were inspected by means of a light optical microscope Leica MEF $4(80 \times)$ to assure that the coating covered the notch completely. After inspection, the coated specimens were maintained under a sustained load of $75 \%$ of the NFS in air to measure the time to rupture/completion of the $200 \mathrm{~h}$ test period. In case of only one of the specimens fracturing within $200 \mathrm{~h}$ of sustained load, the following procedure was applied to the remaining specimens: load every $2 \mathrm{~h}$ in $5 \%$ NFS increments to $90 \%$ of the NFS after completion of the $200 \mathrm{~h}$ period. After $2 \mathrm{~h}$ at $90 \%$, the process was considered non-embrittling if no fracture occurs in the three remaining specimens. If two or more specimens fracture within the sustained load exposure time, the coating process was considered embrittling.

\subsubsection{Axial fatigue strength}

This test is carried out in order to determine if the coating and/or the coating application process modifies the fatigue strength of the substrate material [25]. A sinusoidal load of $20 \mathrm{~Hz}$ and load ratio of $\mathrm{R}=-1$, at room temperature $\left(23 \pm 2{ }^{\circ} \mathrm{C}\right)$ and $35 \pm 3 \%$ humidity was applied for this study and the fatigue strength was considered as the value at which the specimen fractured. Otherwise, the samples were removed after $5 \times 10^{6}$ load cycles. The test was performed on two MTS computer-controlled servohydraulic axial fatigue testing machines (mod. 810). Three groups of fatigue specimens were prepared to obtain S-N curves: uncoated, Cd-plated and Al-slurry coated 4340 steel.

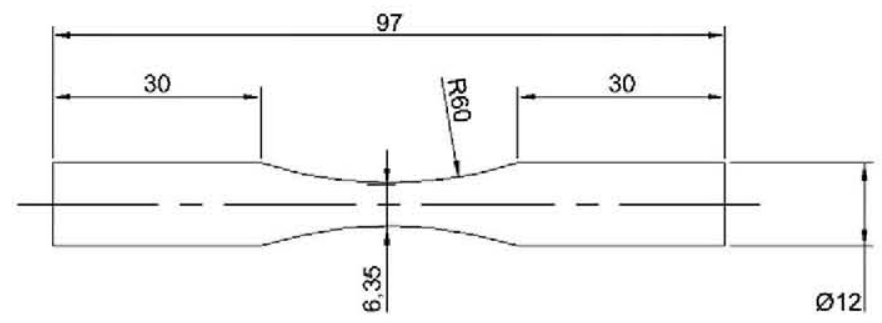

Fig. 3. Fatigue test specimen. All the dimensions are in $\mathrm{mm}$.

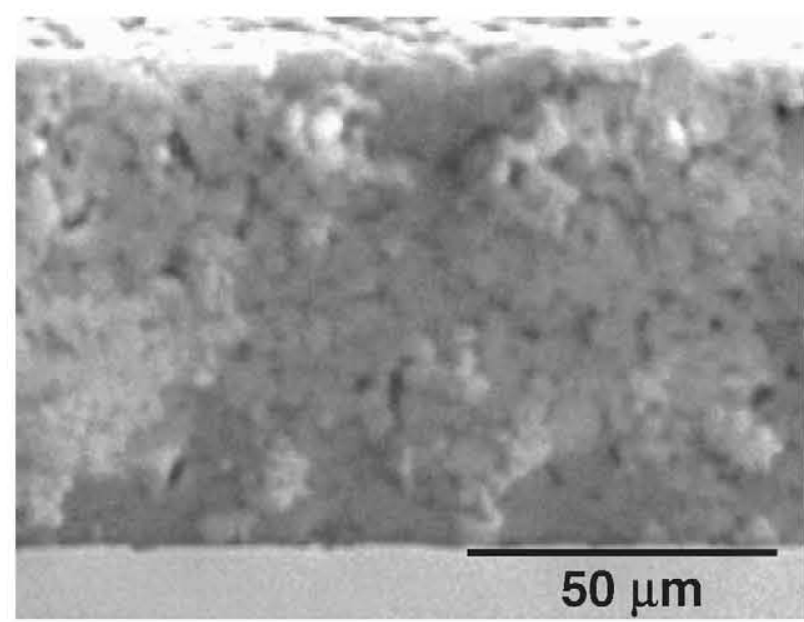

Fig. 4. SEM cross section of as-coated $\mathrm{Al}$ slurry coating.

The fatigue experimental program shown in Table 2 was performed on round specimens with continuous radius between ends, machined according to Fig. 3.

\subsubsection{Roughness measurements}

The surface roughness of both Cd-plated and Al slurry-coated as well as uncoated specimens was for better understanding the fatigue test results. All surface roughness data was obtained by a Taylor Hobson Form Talysurf Profilometer using a $0.8 \mathrm{~mm}$ cut-off.

\section{Results}

\subsection{Coating morphology and thickness}

A commercial Al slurry was applied to AISI 4340 using a spray gun process and was subsequently subjected to a curing heat treatment. The resulting coating is shown in Fig. 4. It consists of a layer of agglomerated Al particles with a thickness of approximately $100 \mu \mathrm{m}$. However, this "as deposited" coating was not electrically conductive likely due to lack of proper contact between the Al particles. Electrical conductivity is an important requirement for most aeronautic components to allow charge dissipation. To densify the coating and ensure particle to particle contact, Al-slurry coated specimens were subjected to glass bead peening (GBP). As a result, the coating became more compact,

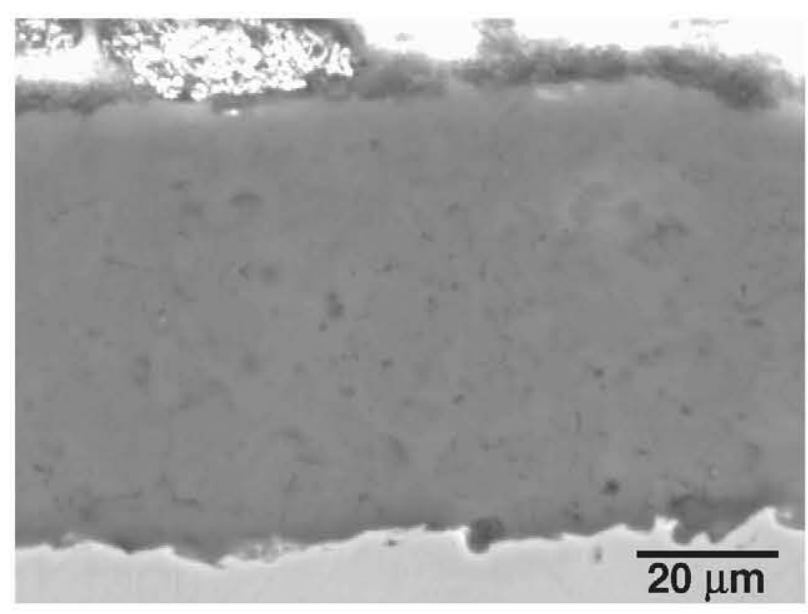

Fig. 5. SEM cross section of GBP Al slurry coating. 


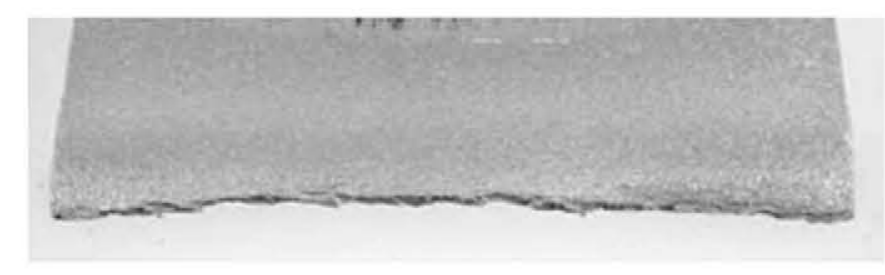

Fig. 6. Fractured GBP Al slurry-coated specimen after repeatedly bending $180^{\circ}$.

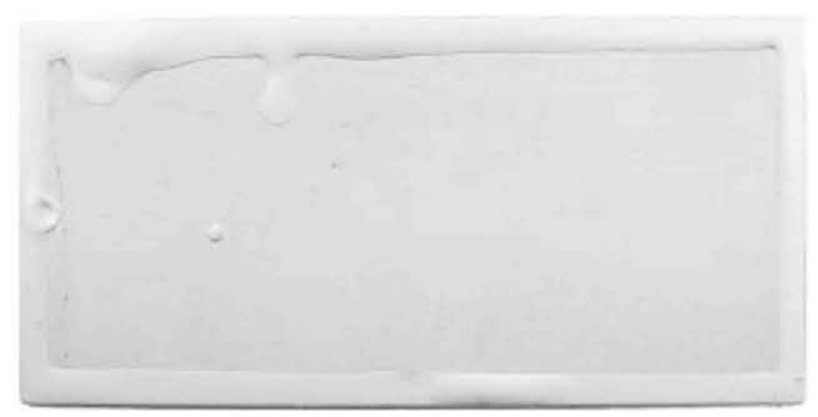

Fig. 7. GPS Al slurry coating painted with chromate-free epoxy primer after immersion in water for $168 \mathrm{~h}$ followed by tape application and removal (ASTM D 3359).

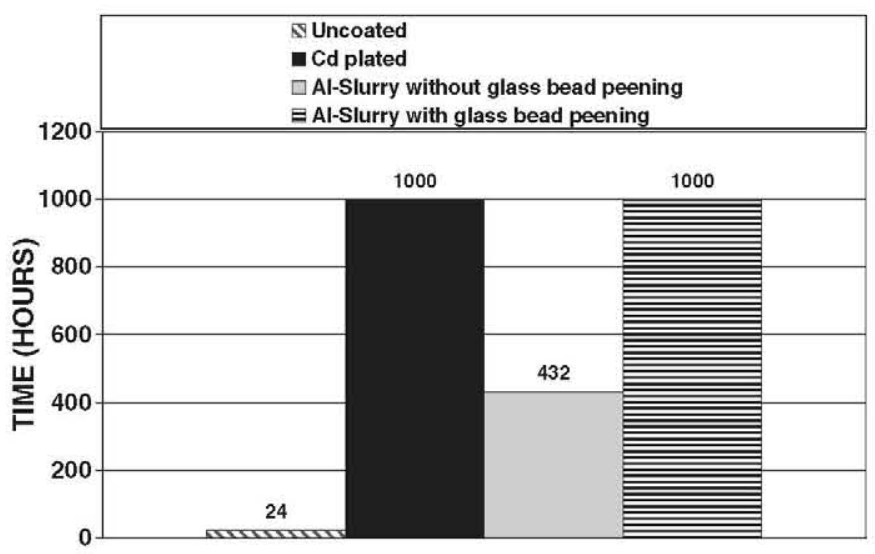

Fig. 8. Hours to failure in salt fog corrosion exposed specimens.

$24 \mathrm{~h}$

$1000 \mathrm{~h}$

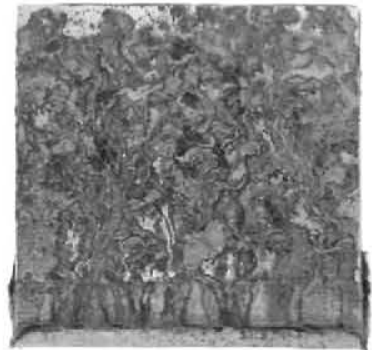

Uncoated

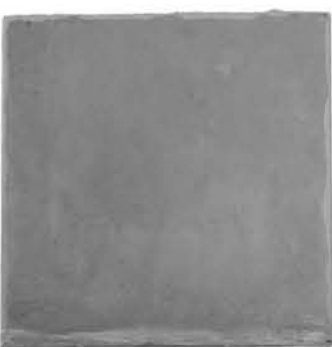

Cd plated

the thickness was reduced to $70 \mu \mathrm{m}$ (Fig. 5) and the coating became conductive (Electrical Resistance $<1 \Omega$ ).

\subsection{Coating-substrate adhesion}

Adhesion of the GBP Al slurry coating was tested by bending a coated AISI 4340 flat coupon as many times as necessary in order to break it. As shown in Fig. 6, no coating delamination or spallation could be observed. The reference $\mathrm{Cd}$ coated specimen exhibited the same behavior. It is noteworthy that similar slurry coatings exhibited cohesion failure when exposed to this test [26].

\subsection{Wet tape paint-coating adhesion}

Cd-coated components are usually painted and the coating-paint adhesion must be sufficiently strong. Coated specimens were painted with a chromate-free epoxy-primer commonly used on aeronautic components. Adhesion was measured after immersing the coated and painted specimens in water using the pull-off tape method. Both the painted GBP Al slurry-coated and Cd-plated specimens remained unaffected, as the paint was not removed from the coating/ plating. Fig. 7 shows the tested GBP Al slurry-coated specimen as a representative image.

\subsection{Unscribed and scribed salt spray fog corrosion resistance}

Uncoated, Cd-plated as well as Al slurry-coated specimens with and without GBP were exposed to a salt fog [20]. Qualitative results were obtained by visual inspection and any sign of pitting, blistering, as well as red rust is considered a failure. Uncoated AISI 4340 exhibited red corrosion products after only $24 \mathrm{~h}$ whereas the unscribed Cd-plated specimens reached $1000 \mathrm{~h}$ without evidence of red corrosion products (Figs. 8 and 9). The surface of the Al slurry-coated specimens that were not subjected to GBP appeared cracked and a reddish coloration became visible at $430 \mathrm{~h}$ in the unscribed specimens, indicating the presence of red rust. However, the GBP samples reached $1000 \mathrm{~h}$ without evidence of red corrosion products. Small amounts of white corrosion products were observed and were identified as Al hydroxides and oxyhidroxides by XRD. Fig. $10 \mathrm{~A}$ and B shows cross section micrographs and elemental mapping of both these tested specimens at the coating-substrate interface, respectively. Coating delamination as well as accumulation of

$432 \mathrm{~h}$

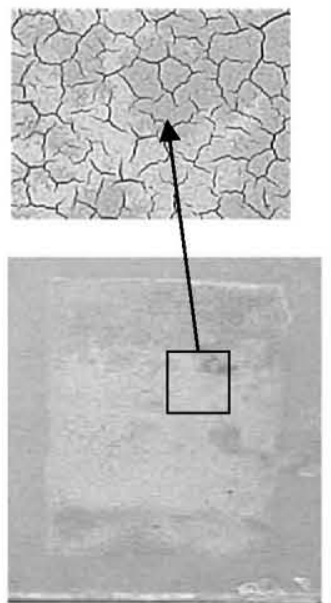
Al slurry-coated without GBP

$1000 \mathrm{~h}$

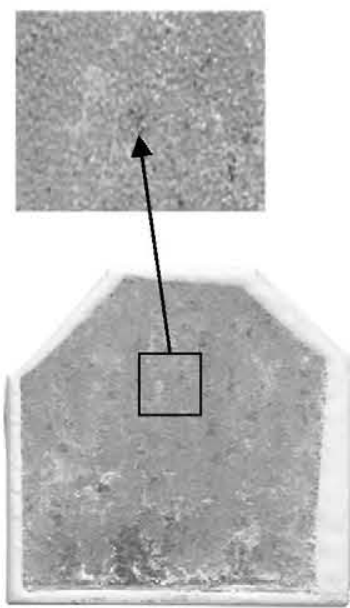

GBP Al slurrycoated

Fig. 9. Salt fog corrosion test results for AISI 4340 specimens after different exposure times. 


\section{A}

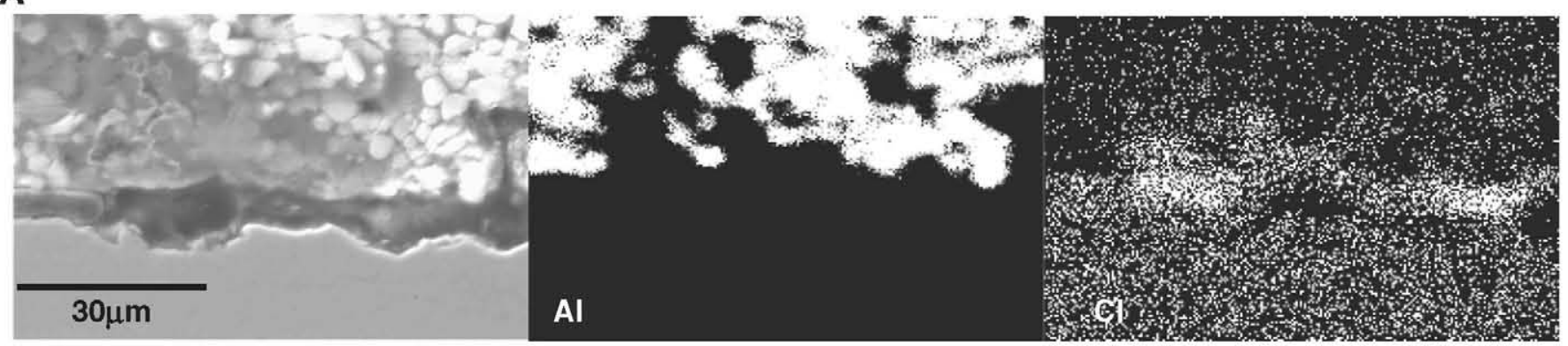

B

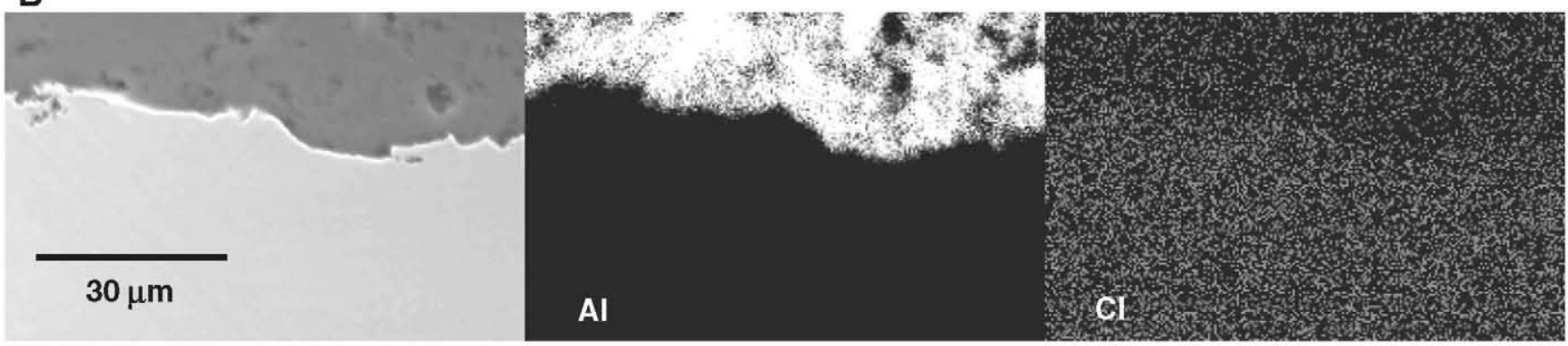

Fig. 10. Cross-section of salt fog corrosion exposed coated AISI 4340 specimens at the coating-substrate interface: A) unpeened Al slurry coating after 432 h of exposure and B) GBP Al slurry coating after $1000 \mathrm{~h}$ of exposure.

Cl-containing species at the coating-substrate interface can be observed on the specimen not subjected to glass beading (Fig. 10A). Moreover, EDS analysis indicated $8 \mathrm{wt} . \%$ of Fe within the Al coating, very likely due to the presence of Fe hydroxides resulting from the corrosion process. These hydroxides, dissolved in water, could easily infiltrate the coating porosity, which can be clearly seen in the micrograph along with the Al particles that constitute the coating. On the other hand, the micrograph of GBP-coated specimen (Fig. 10B) reveals a denser, more compact $\mathrm{Al}$ coating without $\mathrm{Fe}$, delamination or $\mathrm{Cl}$ accumulation at the

A

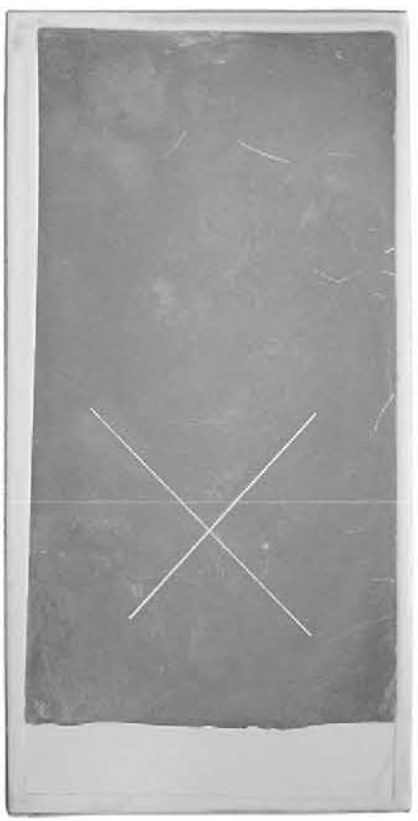

B

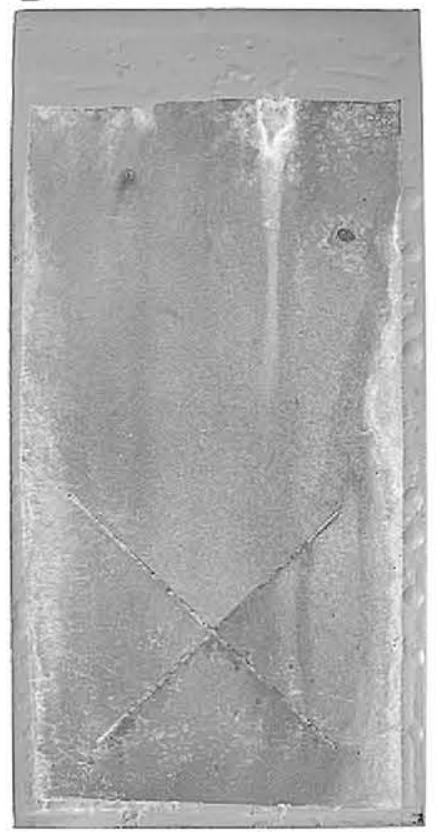

Fig. 11. Salt fog corrosion exposed AISI 4340 scribed specimens after $1000 \mathrm{~h}: \mathrm{A}) \mathrm{Cd}$-plated and B) GBP Al slurry-coated. coating-substrate interface. Therefore, it is clear that GBP densifies the coating and, moreover, also prevents cracking when the slurry is exposed to high humidity levels.

Scribed specimens of both Cd plated and GBP Al slurry-coated specimens were exposed for $1000 \mathrm{~h}$ without the appearance of red rust or coating detachment, as shown in Fig. 11. The GBP Al-slurry coated specimens exhibited white corrosion products in the scribed grooves, which appeared after $24 \mathrm{~h}$ of exposure, indicating formation of aluminum oxides.

\subsection{Fluid corrosion resistance}

Aeronautic components are exposed to a wide variety of liquids currently employed for different purposes such as fuels, antifreeze, hydraulic fluids, lubricants, degreasers, paint strippers, etc. Therefore, coatings employed on such components must be resistant to these fluids. After immersion on the liquids indicated in Table 1 for a total of $168 \mathrm{~h}$, both Cd-plated and GBP Al slurry-coated specimens had a rating of 0 , i.e., no visual changes with respect to the corresponding samples prior to immersion in the test fluids. Moreover, the weight
A

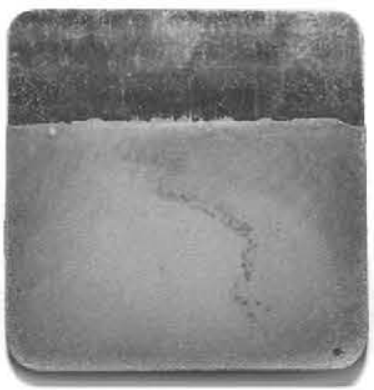

B

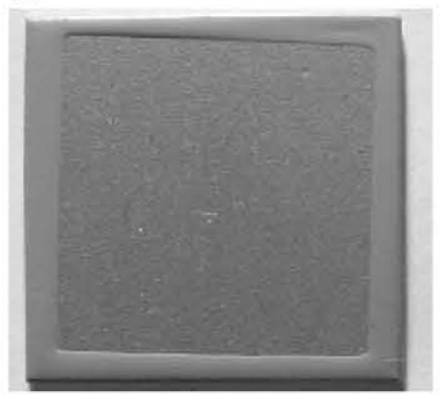

Fig. 12. Representative immersion test results after $168 \mathrm{~h}$ in hydraulic fluid Skydrol LD4: A) Cd-plated and B) Al slurry-coated with glass bead peening. "The top third of the Cd-plated specimens was not coated as specimens were clamped in this zone during coating. 
A

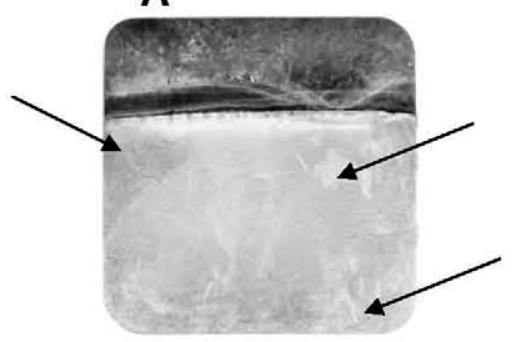

B

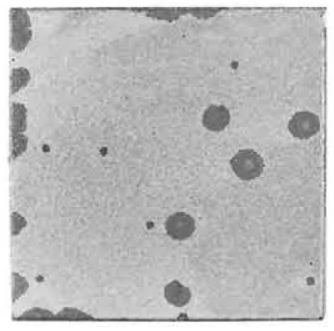

Fig. 13. Representative immersion test results after $168 \mathrm{~h}$ in a paint stripping agent (TURCO 6017): A) Cd-plated (the arrows point highly discolored zones) and B) GBP Al slurry-coated specimens. "The top third of the Cd-plated specimens was not coated as specimens were clamped in this zone during coating.

variations were negligible for both coatings. A representative example is shown in Fig. 12, where photos of both Cd and GBP Al slurry-coated specimens are shown after immersion in the hydraulic fluid Skydrol LD4. However, when exposed to a paint stripping agent (Turco 6017), both coatings failed (168 h of immersion) (see Fig. 13). The Cd-plated specimens appeared highly discolored (more than $25 \%$ of the coated surface) and slightly detached at the top edge, whereas in the Al coated specimens, dark spots appeared likely indicating coating stripped zones. Moreover, both types of coated specimens exhibited weight-losses, higher for the Cd-plated specimens (Fig. 14). Turco 6017 is a Type II remover for amine-cured epoxy paint systems. It is based on formic acid according to the Military Specification for these types of paint removers [27]. Failure of $\mathrm{Cd}$ coatings when exposed to this stripper has also been observed by others [28].

\subsection{Humidity resistance}

Coated specimens were exposed to 10 temperature cycles between 30 and $60{ }^{\circ} \mathrm{C}$ in a $95 \%$ humidity chamber. No swelling or blisters were observed in both Cd-plated and GBP Al slurry-coated specimens, indicating satisfactory humidity resistance as seen in Fig. 15.

\subsection{Galvanic corrosion}

Galvanic corrosion results when two electrochemically dissimilar metallic materials are in electrical contact, and exposed to an electrolyte, with the more anodic material corroding faster than it would if it were not in contact with the other material. To carry out this test, the Al-coated and Cd-plated steel specimens are placed in contact with an

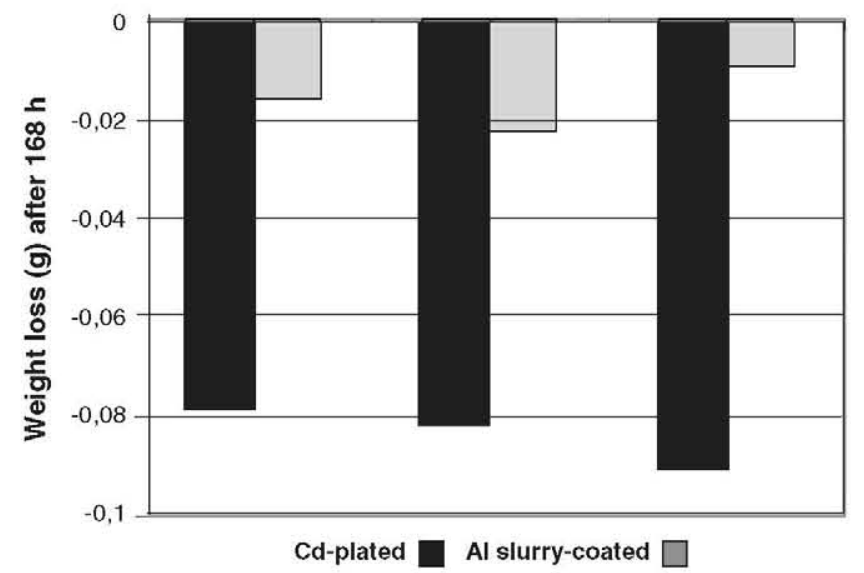

Fig. 14. Weight loss after $168 \mathrm{~h}$ of three sets of Cd-plated and Al slurry-coated specimens immersed in a paint stripping agent (TURCO 6017).
A

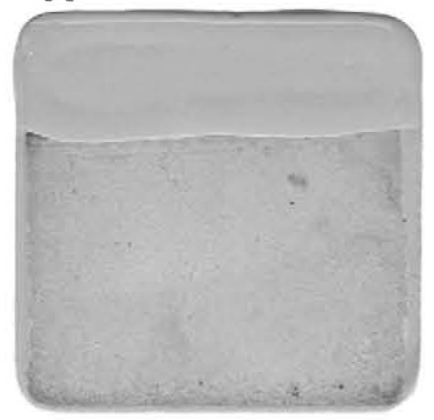

B

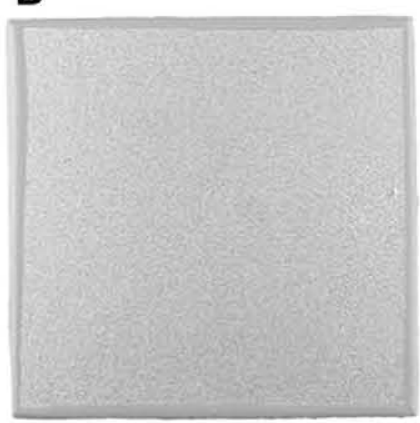

Fig. 15. Coated specimens exposed to 10 temperature cycles between 30 and $60^{\circ} \mathrm{C}$ in a $95 \%$ humidity chamber: A) Cd-plated and B) GBP Al slurry-coated specimens. *The top third of the Cd-plated specimens was not coated as specimens were clamped in this zone during coating.

Al alloy block (2024-T3) as shown in Fig. 1, and the assembly is exposed to a salt fog for one week.

After exposure, discoloration was evident on the Cd coating in contact with the Al alloy, likely as a result of the chromate conversion coating leaching (see Fig. 16). Moreover, white corrosion products could be observed on some isolated spots on the Al alloy block surface that was in contact with the Cd-plated surface. However, no evidence of corrosion could be observed on the 2024-T3 alloy exposed surface (not in contact with the coated surface) and the electrical resistance measurements between the $\mathrm{Cd}$-plated specimen and the Al alloy surfaces confirmed good electrical contact (Table 3).

Regarding the Al slurry-coated specimen, white corrosion products were observed on its surface, whereas loss of metallic shine was observed over all the contact surface of the Al alloy block, as shown in Fig. 16. In addition, abundant white corrosion products identified as Al hydroxides by XRD, could be observed on the surface of the Al block, on areas adjacent to the contact zone, which were probably detached from the Al coating surface. Again, no evidence of corrosion could be observed on the 2024-T3 alloy exposed surface and the electrical resistance measurements also indicated no changes after exposure to salt fog, as seen in Table 3. As expected, the Al coating corrodes sacrificially protecting both the Al alloy directly in contact with the coated surface, as well as the rest of the exposed Al alloy.

It can be concluded that despite the development of large amounts of corrosion products on the Al coatings, no loss of electrical contact was observed. In addition, the $\mathrm{Al}$ alloy block did not experience corrosion.

\subsection{Hydrogen embrittlement}

Hydrogen embrittlement follows a sequence of steps that can be summarized as: 1) hydrogen surface adsorption, 2) transport through the crystal lattice, 3 ) accumulation in preferred points of the internal structure at dislocations, grain boundaries, inclusions, small voids and other microstructural defects that act as traps for hydrogen, and 3) decohesion of the material and its fracture commonly known as delayed fracture phenomena [29]. Depending on the chosen process, coating deposition can cause hydrogen embrittlement by promoting the surface adsorption of hydrogen, which can diffuse through the coating reaching the substrate. For aeronautical applications, it is crucial to determine if a component has been affected by this process, which results in loss of ductility as well as in-service brittle behavior. If this is the case, a specific process including heat treatments, can be designed to remove hydrogen before it causes any permanent damage.

Hydrogen embrittlement testing was carried out on Cd-plated and Al slurry-coated AISI $4340\left(\sigma_{\text {us }}=1200 \mathrm{MPa}\right)$, which is one of the most sensitive steels to suffer delayed fracture induced by hydrogen. 


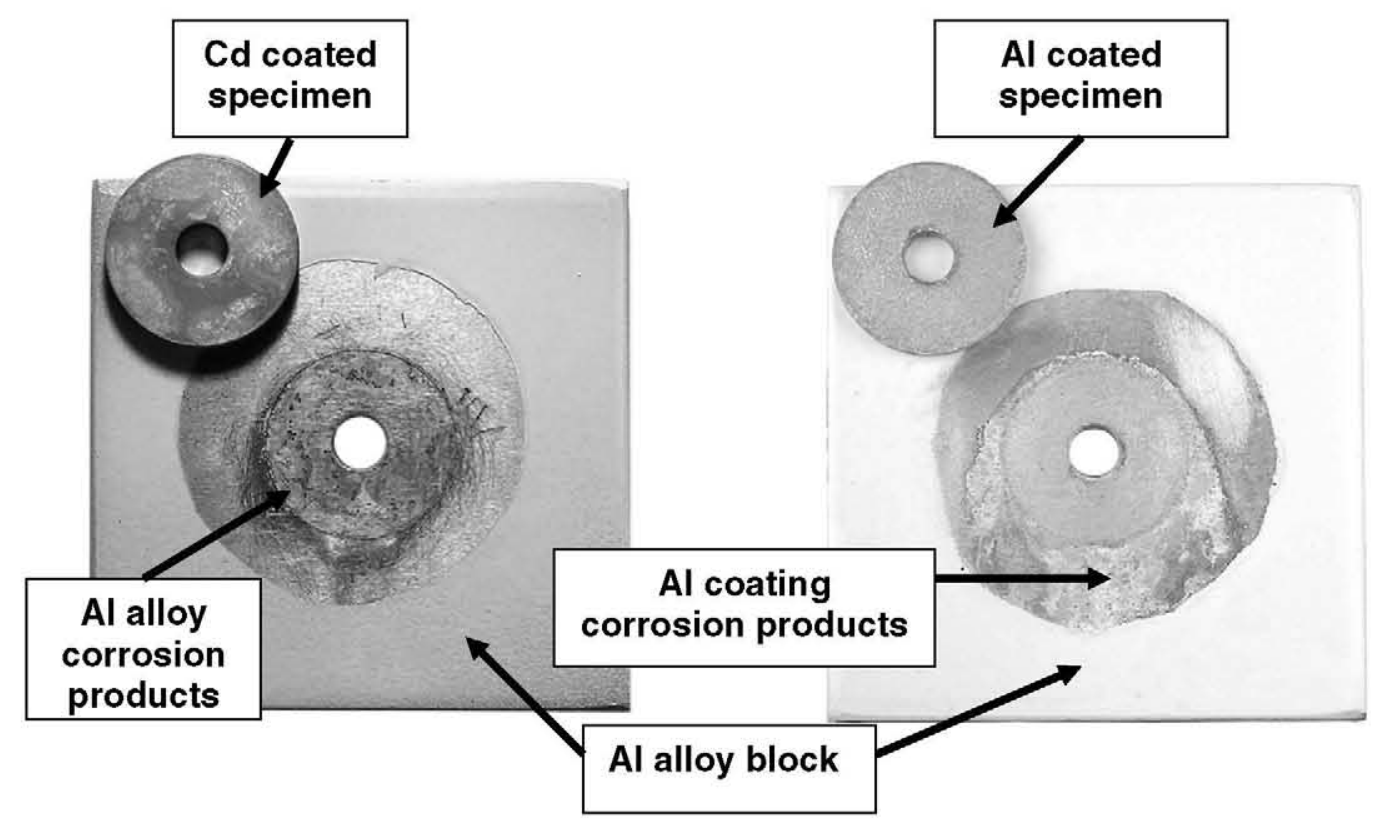

Fig. 16. Galvanic corrosion test results after exposure to salt fog for one week.

During the test, a load equivalent to $75 \%$ of the NFS of the uncoated specimens $(32,960 \mathrm{kN})$ is applied. The Cd-plated specimens were subjected to a dehydrogenation heat treatment that consisted of holding the specimens at $190^{\circ} \mathrm{C}$ for $3 \mathrm{~h}$, whereas the $\mathrm{GBP} \mathrm{Al}$ slurry-coated samples were tested as coated. The test was carried out for $200 \mathrm{~h}$ and none of the specimens exhibited fracture or cracking initiation. Subsequently, all samples were inspected by optical microscopy $(80 \times)$ in order to find cracks and microcracks that could affect the substrate, especially in the notched area. Only some cracks in the slurry coating could be observed (Fig. 17). These specimens were cut lengthwise and inspected at higher magnification $(500 \times)$, confirming that the observed cracks did not propagate into the substrate (Fig. 18). No evidence of internal cracks was found within the substrate. On the other hand, no surface cracks could be observed on the $\mathrm{Cd}$ coatings after the test. Although the elastic modulus of the Al slurry coating was not measured, it must be significantly different from that of the steel, because the coating is much more rigid as it is composed of metallic particles in a ceramic, phosphate based matrix. Likely, these cracks have been generated due to this difference of the elastic modulus.

\subsection{Fatigue test}

Images of Cd-plated and GBP Al slurry-coated specimens are shown in Fig. 19, whereas the corresponding S-N curves for the axial fatigue tests including uncoated AISI 4340 as well as Cd-plated and GBP Al slurry-coated specimens, are represented in Fig. 20.

Both coatings significantly decrease the fatigue resistance of AISI 4340 . As a result of the conventional Cd plating process, atoms of hydrogen generate high local stress and, consequently, reduce the fatigue resistance of high strength steels [30]. However, compared with $\mathrm{Cd}$, the results obtained for the specimens coated with Al slurry

Table 3

Galvanic corrosion test results: electrical resistance measurements after exposure to a salt Fog $(\mathrm{m} \Omega)$.

\begin{tabular}{ll}
\hline Cd coating & Al slurry coating \\
\hline 0.051 & 0.030 \\
0.030 & 0.011 \\
\hline
\end{tabular}

show a smaller decrease in fatigue strength with respect to uncoated AISI 4340.

The decrease in fatigue strength relative to the uncoated substrate may be due to coating irregularities and a high surface roughness. The average surface roughnesses $\left(R_{a}\right)$ of the Al slurry-coated specimens $(3.81 \mu \mathrm{m})$, was higher than that of both the uncoated material $(0.63 \mu \mathrm{m})$ and the $\mathrm{Cd}$-plated specimens $(1.17 \mu \mathrm{m})$. These features are possible cracks or nucleation/initiation sites [31]. Others have also found that Cd plating, as well as electroplated and IVD Al coatings, decreased the rotating bending fatigue strength of AISI 4340 [28].

\section{Discussion}

The reduced corrosion resistance of the unpeened Al slurrycoated specimens prior to exposure could be due to several factors: 1) interconnected porosity and crack development when exposed to salt fog, which allow water to reach the substrate, 2) lack of electrical contact between the coating particles (as clearly shown in the micrographs in Fig. 4 and also evidenced by the low electrical conductivity),

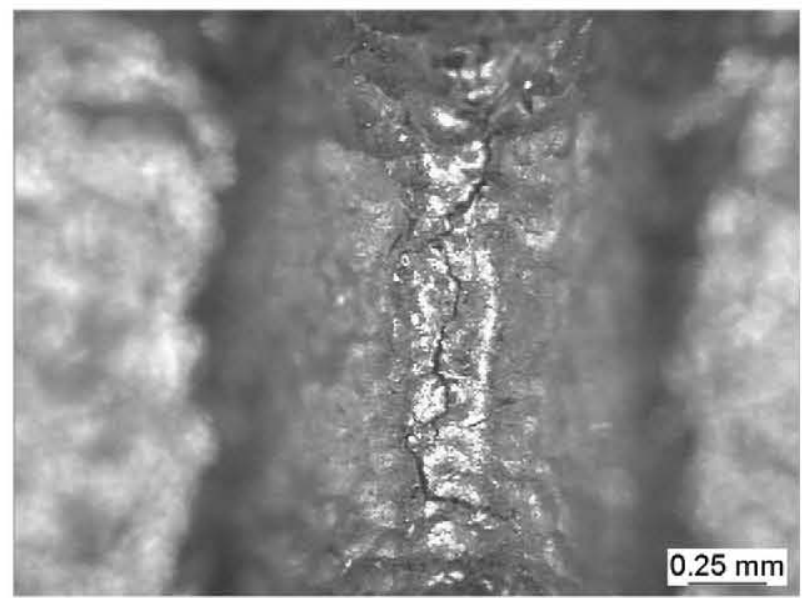

Fig. 17. Circumferential surface cracks in an Al slurry-coated notched sample observed after the embrittlement test. 


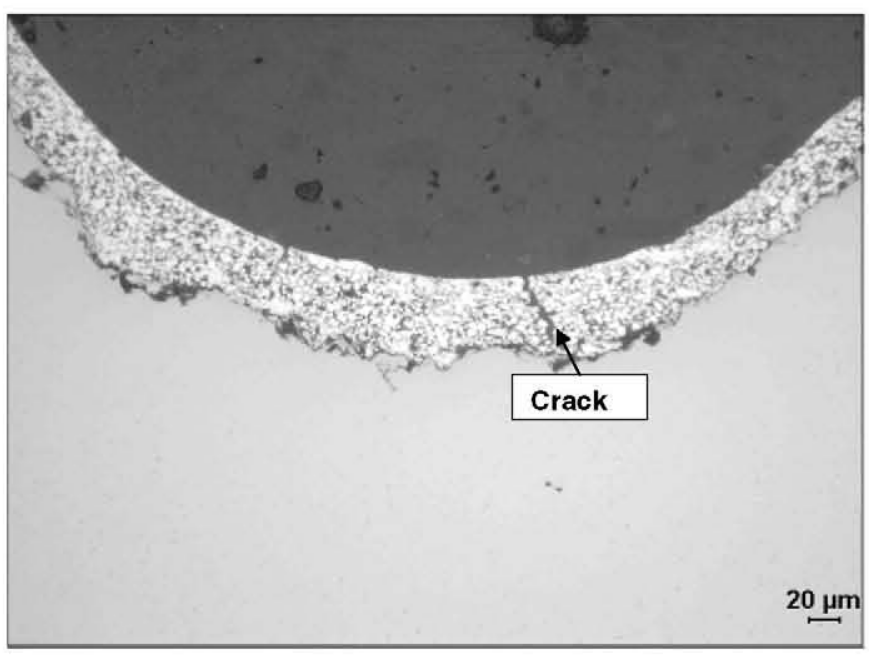

Fig. 18. Cross-section of the $\mathrm{Al}$ slurry coating after the embrittlement test, showing that cracks in the notch affect only the coating.

\section{A) Cd plating, as deposited}

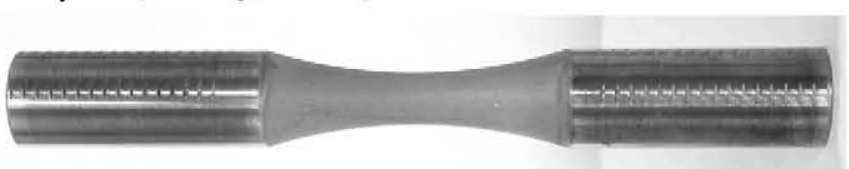

\section{B) GBP Al-slurry}

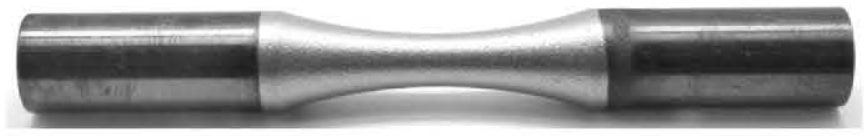

Fig. 19. Coated fatigue test specimens prior to testing. which may limit the degree of cathodic protection in the presence of connected porosity, coating defects, etc., and 3) the increased surface roughness of these coatings as compared to Cd-plated and GBP Al slurry-coated specimens (i.e., corrosion resistance is also associated with surface roughness, the higher the roughness, the higher the corrosion attack due to the higher surface area), [32]. The cracks present in the unpeened $\mathrm{Al}$ slurry coating may actually result from stresses caused by the formation of corrosion products at the coating-surface interface due to water reaching the substrate through interconnected porosity and due to the lack of cathodic protection.

GBP increases the coating density, minimizes the porosity, improves particle to particle electrical contact and reduces roughness. Because the coatings are compact and electrically conductive, corrosion products will not form and cracks do not develop. In any case, the salt fog corrosion results exhibited by the GBP Al slurry coating are outstanding, in particular because no chromate conversion treatment was applied to these coated specimens as opposed to the Cd-plated reference samples. This may be due to the fact that the binder formulation employed to produce the Al slurry coating contains some $\mathrm{Cr}^{\mathrm{Vl}+}(<10 \mathrm{mg} / \mathrm{kg})$ but this amount is well below the "Restriction of Hazardous Substances" (RoHS) Directive limits ( $1000 \mathrm{mg} / \mathrm{kg}$ ) [33]. As well as Cd, chromate conversion treatments are considered a major environmental hazard for aircraft production, maintenance and repair [34].

It is also important to emphasize that the Al slurry coatings do not require a dehydrogenation heat treatment, and moreover, the fatigue strength of the Al slurry-coated specimens is higher than that exhibited by the $\mathrm{Cd}$ plated samples despite the higher surface roughness of the Al-slurry coatings [31]. Moreover, although the effect of the Al coating applied by slurry was to decrease the axial fatigue strength of AISI 4340 steel, the decrease in strength was lower than that observed for Cd-plated specimens.

Other than being significantly less harmful for human health and the environment, the slurry application process is also practical and more cost-effective. Large components can be coated "in situ" and the amount of residue produced by the overall coating process is significantly lower than that produced by electroplating.

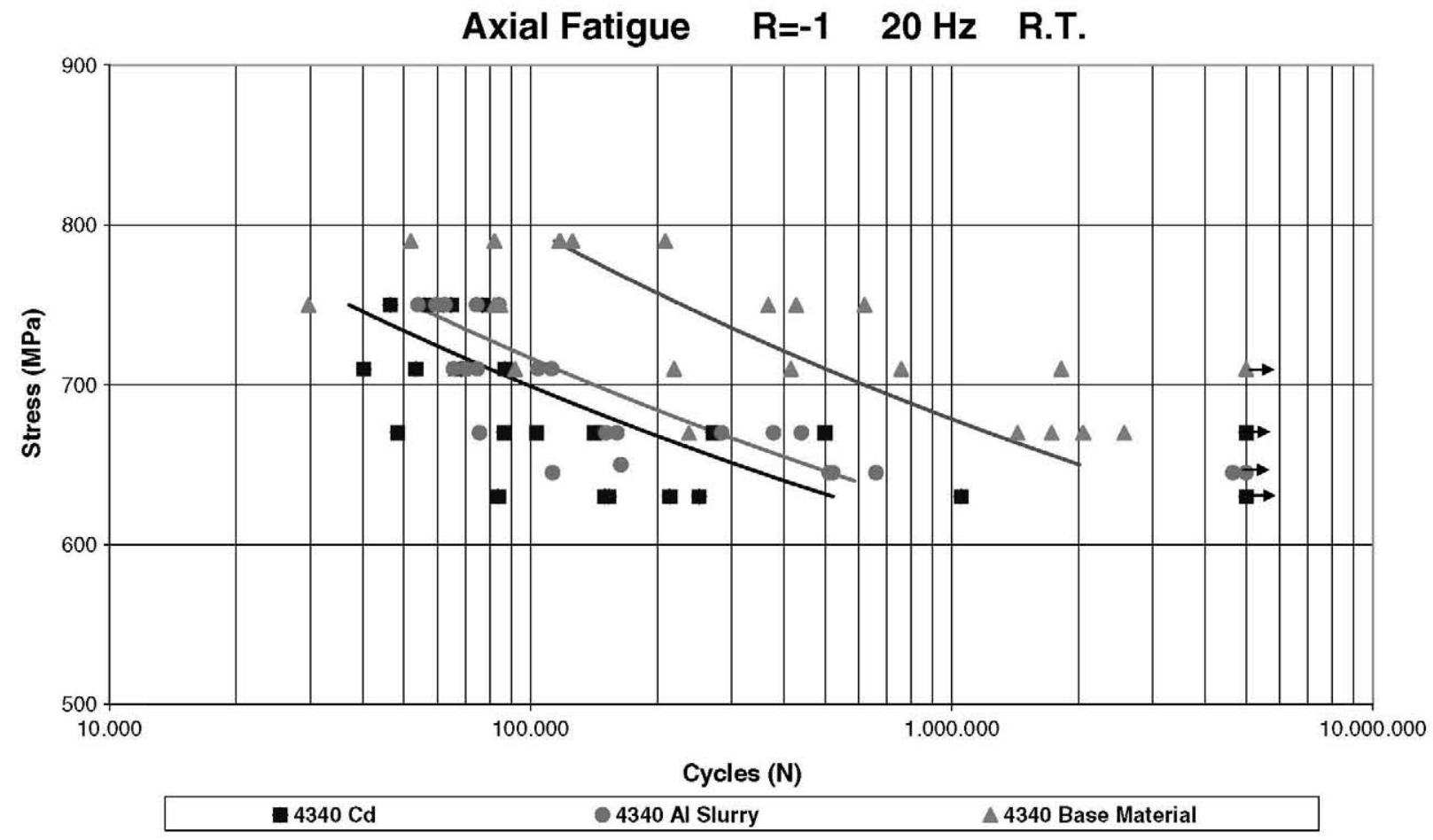

Fig. 20. S/N data for uncoated as well as Cd and GBP Al-slurry coated AISI 4340. 


\section{Conclusions}

Al coatings can be easily deposited and processed by application of slurries followed by moderate temperature curing. These as-deposited coatings are not very dense and do not reach $1000 \mathrm{~h}$ corrosion resistance when tested in salt fog. However, if the coating is glass bead peened, a very dense, corrosion resistant coating is obtained. A thorough testing program has demonstrated that overall, these GBP Al slurry coatings exhibit comparable or better performance and properties than Cd-plated coatings, meeting the aeronautic requirements in all of the tests carried out in this work. Moreover, in contrast to the $\mathrm{Cd}$-plated coating, it does not require a chromate conversion treatment in order to achieve the required salt fog corrosion resistance.

\section{Acknowledgments}

The authors wish to acknowledge Max Morant from Morant \& Morant for his generous contribution to this project as well as the personnel of the Metallic Materials Area (MMA) and Protective Materials Laboratory in INTA, in particular F. Longo (present MMA head) for collaborating in many different ways with this project and $\mathrm{M}$. Hernández for the XRD work confirming the corrosion products. The members of the RAMPE team (CESA, SENER, ITP, GUTMAR, TEKNIKER, AERNNOVA) are thanked for a very fruitful collaboration and the Ministry of Education and Science for partial financial support (project CIT-3702002005-18). Finally, our "retired boss" A. Sánchez Pascual deserves a special acknowledgement for his enthusiasm and strong support of this project.

\section{References}

[1] American Occupational Safety \& Health Administration (OSHA), http://www. osha.gov/SLTC/cadmium/index.html, August 242006.

[2] Nordic Council of Ministers, www.who.int/ifcs/documents/forum5/NMR_cadmium. pdf, 2003.

[3] D.R. Gabe, Surf. Eng. 10 (1994) 41

[4] E.W. Brooman, Metal Finishing 98 (2000) 42

[5] D.E. Hall, Plating Surf. Finishing $70(1983) 59$.

[6] L. Tran, http://www asetsdefense.org/documents/Workshops/SustainableSurface Engineering2009/Agenda/Thursday/Tran\%20-\%20For\%20Posting.pdf, 2009

[7] A. Conde, M.A. Arenas, J.J. de Damborenea, Corros. Sci. 53 (2011) 1489.
[8] S.N. Indumathi, T. Vasudevan, S. Sundarrajan, B.V. Subba Rao, C.V.S. Murthy, D.R. Yadav, Metal Finishing 109 (2011) 15.

[9] E.N. Beck, in: Report No. NAWCADPAX/TR-2006/164, Naval Air Warfare Centre Aircraft Division, Patuxent River, MD, 2007

[10] E.U. Lee, A. Hilgeman, E. Beck, S. Brown, C. Matzdorf, in: Proceedings of the TRI_SERVICE Corrosion Conference 2007, 2007, p. 1.

[11] V. Holmes, J.J. Reilly, "The Substitution of IVD Al for Cadmium", Report ESL-TR-90-28, McDonnel Aircraft Company, St Louis MO, May 1990.

[12] Q. Yu, J. Deffeyes, H. Yasuda, Prog. Org. Coat. 42 (2001) 100.

[13] R. Mason, M. Neidbalson, M. Klingenberg, Metal Finishing (March 2010) 13.

[14] A. Agüero, M. Garcia, M. Gutiérrez, Mater. Corros. 56 (2005) 937.

[15] S. Gu, S. Maeng, Y. Suh, R.A. Levy, D.L. Deavenport, F.J. Gómez, S.S. Newberg, E.W. Brooman, E.S. Berman, J.J. Kleek, J.H. Beatty, A.S. Schwartz, S.P. Gaydos, Chem. Vapor Deposition 16 (2010) 231.

[16] M.F. Mosser, in: Proceedings of the 26th Annual AerospacelAirline Plating \& Metal Finishing Forum \& Exposition Tulsa, Oklahoma, 1990, (900968).

[17] A. Agüero, C. Blanco, M. Garcia, M. Gutierrez, in: Proceedings of the "X Congreso Nacional de Materiales", San Sebastián, Spain, 2008, p. 1005.

[18] ASTM, "Standard Practice for Qualitative Adhesion Testing of Metallic Coatings", B571-2003.

[19] ASTM D3359, "Standard Test Methods for Measuring Adhesion by Tape Test", 2002.

[20] ASTM, "Standard Practice for Operating Salt Spray (Fog) Apparatus", B117-2001

[21] ASTM, "Standard Practice for Total Immersion Corrosion Test for Aircraft Maintenance Chemicals", F483-2002.

[22] MIL-STD-810F-2000. "Environmental Engineering Considerations and Laboratory Tests". Test Method 507.5. "Humidity".

[23] High Strength Steel Joint Test Protocol for Validation of Alternatives to Low Hydrogen Embrittlement Cadmium for High-Strength Steel Landing Gear and Component Applications, The Boeing Company, July 31 2003. http://www.mendeley $\mathrm{com} /$ research/highstrength-steel-joint-test-protocol-for-validation-of-alternativesto-low-hydrogen-embrittlement-cadmium-for-highstrength-steel-landing-gear-andcomponent-applications- 1 .

[24] ASTM, "Standard Test Method for Mechanical Hydrogen Embrittlement Evaluation of Plating/Coating Processes and Service Environments", F519-2006.

[25] ASTM, "Standard Practice for Conducting Force Controlled Constant Amplitude Axial Fatigue Tests of Metallic Materials", E466-2002.

[26] General Administration Services - Task Order Number: 5TS5702D035H Testing Cadmium Plating Alternatives, March 2003.

[27] ASTM, Military Specification: Remover, acid activated, for amine-cured epoxy coating systems, (AS)-1991.

[28] C.J.E. Smith, http://www.garteur.eu/Technical\%20Reports/SM_AG-17_TP-128 OPEN.pdf, 2001([WW] MIL-STD-889).

[29] T.J. Carter, L.A. Cornish, Eng. Fail. Anal. 8 (2001) 113.

[30] H.J.C. Voorwald, M.P. Peres, M.Y.P. Costa, M.O.H. Cioffi, J. Mater. Sci. 45 (2010) 6094.

[31] R.C. Souza, H.J.C. Voorwald, M.O.H. Cioffi, Surf. Coat.Technol. 203 (2008) 191.

[32] E. Budke, J. Kremple-Hesse, H. Maidhof, H. Schüssler, Surf. Coat.Technol. 112 (1999) 108 .

[33] Restriction of Hazardous Substances Directive, European Union directive 2002/95/EC.

[34] G. Bierwagen, R. Brown, S. Hayes, Prog. Org. Coat. 68 (2010) 48. 